\title{
STOURBRIDGE DENTIST RETIRES AFTER 39 YEARS
}

Dentist Iain Dale has retired after 39 years of treating patients at Worcester Street Dental Centre and Stourcote Dental Practice.

Dr Dale has jointly owned the two practices since 2000, working with close friend and dental surgeon Rob Payne, and employing 21 people across the two locations, responsible for the dental care of hundreds of patients every week in the West Midlands. He also chaired the Local Dental Committee for five years.

Dr Dale said: 'I want to say a big thank you to all the patients for their cards and good wishes [...] now is the time to do more skiing and travelling, watching the "Sky Blues" with my daughter Imogen and completing the 268-mile Pennine Way walk with my wife Julia.'

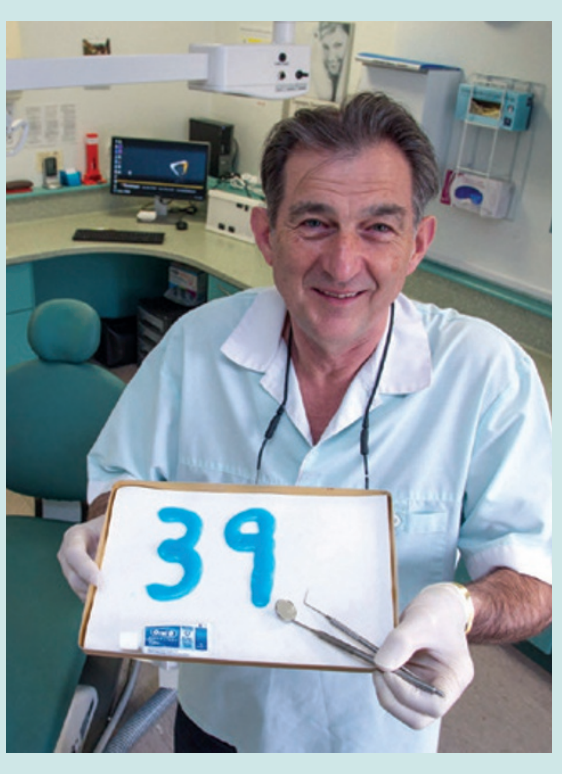

\section{SCOTTISH MOUTH CANCER CHARITY SPONSORS GLOBAL FORUM}

The Scottish charity Let's Talk About Mouth Cancer were proud to be an intellectual sponsor of the inaugural Global Oral Cancer Forum (GOCF) held on 4-5 March 2016 in the Kimnel Centre at New York University. The five trustees from the charity (pictured) joined 200 delegates of diverse clinical and non-clinical backgrounds from 33 countries to work on reducing the global oral cancer burden which claims the lives of 150,000 people each year.

Two posters detailing the findings from the Let's Talk About Mouth Cancer public awareness and empowerment campaigns delivered in Edinburgh and Dundee were presented. These were well received and garnered interest from delegates of various backgrounds and nationality.

According to Mr MacKessack-Leitch, the take home message for the team was the importance of advocacy to politicians, health authorities and health professionals to make mouth cancer prevention, detection and early referral a priority. The next steps for the charity will aim to meet these challenges and report back to the next GOCF provisionally scheduled for two years' time.

www.letstalkaboutmouthcancer.co.uk

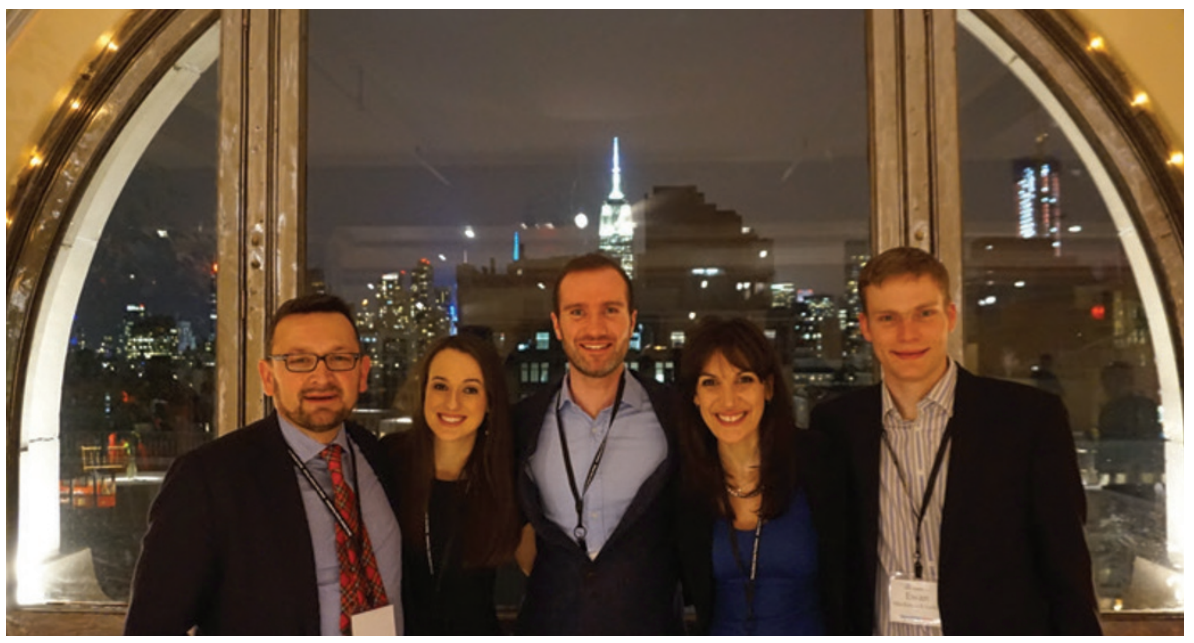

(I-r) Victor Lopes, Orna Ní Choileáin, Niall Mc Goldrick, Stephanie Sammut and Ewan MacKessack-Leitch from Let's Talk About Mouth Cancer 